\title{
Drug Interactions in Iranian Veterans With Chronic Spinal Cord Injury - A Descriptive Study
}

\author{
Ashkan Divanbeigi ${ }^{1,2}{ }^{\circledR}$, Amir Saied Seddighi $^{10}$, Sepideh Amiri ${ }^{2}$, Shiva Jamshidi ${ }^{1}$, Hesam Rahimi Baghdashti ${ }^{1}$, \\ Afsoon Seddighi ${ }^{1 *(10}$
}

${ }^{1}$ Functional Neurosurgery Research Center, Shohada Tajrish Comprehensive Neurosurgical Center of Excellence, Shahid Beheshti University of Medical Sciences, Tehran, Iran.

${ }^{2}$ Shefa Neuroscience Research Center, Khatam Alanbia Hospital, Tehran, Iran.

\begin{abstract}
Background: Veterans with chronic spinal cord injury usually have various comorbidities. They are, therefore, visited by different doctors and use different medications. It is necessary to monitor the health of these veterans. One of the important issues in this regard is the attention to drug interactions. The purpose of this study was to investigate the drugs used and their interactions. Methods: This descriptive study of the cross-sectional studies was carried out retrospectively in 2015 under the Shefa Neuroscience Research Center's supervision, examining the medical records of veterans with spinal cord injury participating in the health screening program at Khatam Alanbiya hospital in Tehran. Demographic data, comorbidities, used drugs, and the level of involvement collected. According to the FDA, drug interactions among the drugs used for each patient has evaluated and classified into three severe, moderate, and weak groups. SPSS v. 21 analyzed data.

Results: The study population consisted of 404 men, ranging in age from 41 to 74 , with a mean of $51.6 \pm 6.4$ years. One hundred forty-two of them (35.1\%) had a complete injury, and 262 veterans $(64.8 \%)$ had an incomplete injury. Only 17 veterans $(4.2 \%)$ had no drug interactions. The number of drug interactions varied from 1 to 38 , with an average of $5.9 \pm 12.8$ interactions per patient. The total number of interactions was 2856 , of which $32.5 \%$ were weak, $55.3 \%$ moderate, and $12.2 \%$ severe, with a $95 \%$ confidence interval. Among the severe drug interactions in the study, the highest number belonged to the antidepressant drugs.

Conclusion: This study highlights the necessity of developing a strategy for investigating and preventing drug interactions in veterans with chronic spinal cord injury. It has recommended that physicians pay more attention to other medications used by the patient and prescribe as little as possible of the drug and the drug with the least number of interactions.

Keywords: Veteran; Spinal cord injury; Drug; Comorbidity.
\end{abstract}

\author{
*Correspondence to \\ Afsoon Seddighi, \\ Functional Neurosurgery \\ Research Center, Shohada \\ Tajrish Comprehensive \\ Neurosurgical Center of \\ Excellence, Shahid Beheshti \\ University of Medical Sciences, \\ Tehran, Iran. \\ Phone \& fax: +982122724214 \\ Email: afsoun.seddighi@sbmu. \\ ac.ir
}

Published online 28 September, 2020

Citation: Divanbeigi A, Seddighi AS, Amiri S, Jamshidi S, Rahimi Baghdashti H, Seddighi A. Drug Interactions in Iranian Veterans With Chronic Spinal Cord Injury - A Descriptive Study. Clin Neurosci J. 2020;7(4):196-200. doi:10.34172/icnj.2020.25.

\section{Introduction}

Approximately 2000 people are living in Iran with spinal cord injuries related to the war. The average life expectancy of people with spinal cord injury is approximately $90 \%$ of normal individuals one year after the injury. ${ }^{1,2}$ A spinal cord injury that lasts more than a year is called a chronic spinal cord injury, which can cause various physical and mental conditions in the long term. The Veterans Spinal Cord Injury Center has widely implemented the screening program for injured veterans in the health field. In this program, veterans are periodically visited at home and examined each year in specialized medical centers. ${ }^{3,4}$ Patients with spinal cord injury take more medication because of chronic and comorbid problems. During these visits, it felt that the number of drugs used by these patients was much higher than the normal form. This was a sensitive issue and should investigate.

Whenever the use of a second drug alters the specific effect of a drug prescribed for a patient, drug interference occurs. A variety of drug interactions causes many of the side effects of the drug. It can found in various forms, such as drug interactions with drugs, drugs with foods, drugs with environmental factors, and drugs with diseases., ${ }^{5,6}$ Many physicians and pharmacists do not spend the time needed to monitor all prescription and over-the-counter medications closely, and this inaccuracy in prescribing medications, especially for patients on a multi-drug regimen, can lead to drug interactions. ${ }^{7,8}$ Patients with chronic refractory diseases require multiple medications because of the long course of the disease that usually leads

(C) 2020 The Author(s). This is an open access article distributed under the terms of the Creative Commons Attribution License (http:// creativecommons.org/licenses/by/4.0/), which permits unrestricted use, distribution, and reproduction in any medium, provided the original work is properly cited. 
to the addition of other diseases to the primary problem. The advent of drug interactions in these patients can affect the extent and duration of the effect of the drug, meaning that none of the drugs has the full expected effects. ${ }^{9,10}$ Drug interactions can also lead to a new disease, impaired drug tolerance, and deprivation syndrome, leading to physician misstatement in the diagnosis of the disease. It is more likely to be intolerant to drugs that have many drug interactions with other medications that mistakenly prescribed, and sometimes these interactions may lead to a new disease in the patient that may lead to more medications administered to the patient. In addition to damaging different organs, this issue increases the cost of the patient and their supportive treatment system. ${ }^{11,12}$

This study aimed to investigate possible drug interactions in veterans with chronic spinal cord injury referred to Tehran Khatam Alanbia hospital during the 2015 screening program.

\section{Materials and Methods}

This descriptive study of the cross-sectional studies was carried out retrospectively in 2015 under the Shefa Neuroscience Research Center's supervision, examining the medical records of veterans with spinal cord injury participating in the health screening program at Khatam Alanbiya hospital in Tehran. Integration criteria At least one year has passed since the spine injury, there is no date of hospitalization and mechanical ventilation three months before entering the center. Demographic data, comorbidities, used drugs, and the level of involvement collected. The types of injuries were determined based on the severity of the injuries caused by full or partial injuries and injuries to the neck, thoracic and lumbosacral, quadriplegia, and paraplegia. The number, type, and amount of all medications were collected by studying case files and questionnaires. According to the Food and Drug Administration (FDA), drug interactions among the drugs used for each patient has evaluated and classified into three severe, moderate, and weak groups. In severe interactions, simultaneous administration of two drugs is prohibited, in moderate interference, with caution, and in poor interference, the patient should inform of any potential complications. ${ }^{13}$

The data has recorded in each patient's file. Demographic data, medications, drug interactions, drug, and severity of drug interactions were analyzed by SPSS software version 21. Data were reported as percent, mean and standard deviation.

\section{Results}

The study population consisted of 404 men, ranging in age from 41 to 74 , with a mean of $51.6 \pm 6.4$ years. The average post-SCI period was $29.09 \pm 5.07$ years. Thirtyfour veterans $(8.4 \%)$ had quadriplegia, and 370 (91.6\%) were paraplegic. One hundred forty-two of them (35.1\%) had a complete injury, and 262 veterans (64.8\%) had incomplete injuries. Comorbidities have listed in Table 1. The number of drugs used was 3 to 28 , with $5.3 \pm 10.1$ types of drugs per day.

In the study population, antidepressants used more than other drugs. Three hundred seventy-one people were taking antidepressants. Antacid drugs 88.6\%, Anticonvulsants 79.2\%, Antihyperlipidemic agents $68.3 \%$, and Antihypertensive agents $65.6 \%$, Vitamin and mineral combinations $65.1 \%$, and other drugs were next (Table 2). Only 17 veterans $(4.2 \%)$ had no drug interactions. The number of drug interactions varied from 1 to 38 , with an average of $5.9 \pm 12.8$ interactions per patient. The total number of interactions was 2856 , of which $32.5 \%$ were weak, $55.3 \%$ moderate, and $12.2 \%$ severe, with a $95 \%$ confidence interval.

Among the severe drug interactions in the study, the highest number belonged to the antidepressant drug group. Among the 349 severe interactions, there was at least one antidepressant drug in 230 cases, of which 126 were interactions between the two antidepressants, the most common antidepressant drug being the two SSRIs (selective serotonin reuptake inhibitor) and TCAs (tricyclic antidepressant) with 92 interferences.

The most common severe interactions were fluvoxamine and nortriptyline. Valproic acid and Clonazepam in the moderate group, Ranitidine, and Acetaminophen codeine, had the mildest group interactions.

\section{Discussion}

According to the results of this study, almost all veterans with spinal cord injury had drug interaction. This finding is important because these interactions can not only lead to prolonged illness and failure to respond appropriately to treatment, but may also cause the patient to discontinue one or more medications, or may need to add medications. Since patients' health is the top priority of the health care system; therefore, drug interactions and their complications should avoid for faster improvement. Drug interactions are also economically important in

Table 1. Comorbidities of Veterans With Chronic Spinal Cord Injury

\begin{tabular}{lcc}
\hline Problem-Related to... & No. & $\%$ \\
\hline Psychiatry & 284 & 70.3 \\
Cardiovascular & 243 & 60.1 \\
Pulmonary & 277 & 68.6 \\
Gastroenterology & 281 & 69.6 \\
Dermatology & 232 & 57.4 \\
Metabolic & 126 & 31.2 \\
Nephrology & 260 & 64.4 \\
Neurology & 68 & 16.8 \\
Musculoskeletal & 264 & 65.3 \\
Ophthalmology & 105 & 26.0 \\
\hline
\end{tabular}


Table 2. Type of Drugs Used by Veterans With Chronic Spinal Cord Injury

\begin{tabular}{|c|c|c|}
\hline Drug Category & No. & $\%$ \\
\hline Antidepressants & 371 & 91.8 \\
\hline Antacids & 358 & 88.6 \\
\hline Anticonvulsants & 320 & 79.2 \\
\hline Antihyperlipidemic agents & 276 & 68.3 \\
\hline Antihypertensive agents & 265 & 65.6 \\
\hline Vitamin and mineral combinations & 263 & 65.1 \\
\hline Miscellaneous $\mathrm{Gl}$ agents & 250 & 61.9 \\
\hline Cardiovascular agents & 220 & 54.5 \\
\hline Antiplatelet agents & 210 & 52.0 \\
\hline Uterotonic agents & 199 & 49.3 \\
\hline Laxatives & 190 & 47.0 \\
\hline Antiasthmatic combinations & 187 & 46.3 \\
\hline Anxiolytics, sedatives, and hypnotics & 178 & 44.1 \\
\hline Muscle relaxants & 167 & 41.3 \\
\hline Antidiabetic agents & 142 & 35.1 \\
\hline Analgesics & 111 & 27.5 \\
\hline Anticoagulants & 95 & 23.5 \\
\hline Dermatological agents & 81 & 20.0 \\
\hline Antigout agents & 74 & 18.3 \\
\hline Antipsychotics & 59 & 14.6 \\
\hline Herbal products & 40 & 9.9 \\
\hline Ophthalmic agents & 34 & 8.4 \\
\hline Glucocorticoids & 32 & 7.9 \\
\hline Antiarrhythmic agents & 25 & 6.2 \\
\hline Antibiotics & 23 & 5.7 \\
\hline Bone resorption inhibitors & 23 & 5.7 \\
\hline Antiemetic agents & 10 & 2.5 \\
\hline CNS stimulants & 7 & 1.7 \\
\hline
\end{tabular}

addition to the risks to patients' health and may increase the frequency of patient referrals and unnecessary paraclinical testing and thus increase medical costs.

The high cost of using overlapping drugs comprises a high percentage of the healthcare support budget of these patients, which may lead to a reduction in the number of services needed in this group. ${ }^{14,15}$

The results confirm the findings of a study conducted on 150 wounded in Tehran, showing that 148 patients had interfered with their medication. ${ }^{16}$ According to the results of this study, the more drugs the patient uses, the greater the chance of drug interference. Other studies confirm this result, for example, in one study showing a linear relationship between the number of drugs and drug interactions. Another study also found that 15 percent of people taking multiple medications had significant and dangerous drug interactions ${ }^{17-19}$ Some patients take other medicines arbitrarily, regardless of the drug interference problem, with the current prescription medication, and here the issue of the physician's attention to other medicines used by the patient becomes apparent. ${ }^{12}$

Our study showed that about $12 \%$ of all drug interactions in patients are of severe interactions. In this regard, other studies' results were varied and more or less than the results obtained in this study. Some studies of patients with chronic diseases have reported very few drug interactions. ${ }^{20-23}$ A study of antidepressant drug interactions with antihypertensive and hypoglycemic drugs found that of the 663 patients under study, only 29 patients had drug interactions. ${ }^{24}$ While some other studies show that patients with chronic diseases are more susceptible to multiple drug interactions, for example, a study of US war casualties found that the effect of specific drug components has led to specific biological changes in about $90 \%$ of people receiving the drug. In that study, the highest number of drug interactions related to antidepressants ${ }^{25}$ is similar to the present study results. Our study also showed that among antidepressants, most interactions were between tricyclic antidepressants and selective serotonin reuptake inhibitors. In other studies, antidepressants identify as the most common drugs with interactions. In one study of more than 1000 US war casualties, $62 \%$ of patients under the age of 60 and $96 \%$ of patients over the age of 60 were taking specific antidepressant medications, the majority of those who observed drug interactions consumed 5 to 6 drugs, including antidepressants. ${ }^{25-27}$ Another study in Australia found that $15 \%$ of combat casualties use at least one antidepressant, and only $8 \%$ of them have drug interactions. ${ }^{28}$ While our study showed that $91 \%$ of patients took antidepressants, and most of them had drug interactions.

Many of the drugs used to treat veterans with chronic illnesses are specific components of the drug, given their diseases that are not commonly seen in other social groups. Some of the specific drug components in these patients can lead to specific biological changes that judge the extent of the interference more complicated. In the case of antidepressants with the most interactions, it may seem that the problem may solve by prescribing single-family drugs rather than multiple families. While single-family drugs classified according to one of the pharmacological aspects of the drug, other directions may differ. ${ }^{26-29}$

\section{Conclusion}

The results of this study highlight the necessity of developing a strategy for investigating and preventing drug interactions in war injuries. Also, to reduce the side effects of drug interactions at the time of administration of the new drug, it is necessary to consider the biological differences in these patients due to taking several drugs.

The list of drug interactions is pervasive, with some added over time. Therefore, it is advisable to use the available scientific resources in groups at higher risk for 
adverse drug reactions to ensure drug interference.

It recommended that physicians pay more attention to other medications used by the patient and consider their drug interactions. Also, prescribe as little as possible of the drug and the drug with the least number of interactions.

\section{Conflict of Interest}

The authors declare that they have no conflict of interests.

\section{Acknowledgment}

In writing this study, the authors gratefully thank Shefa Neuroscience Research Center, Also we honor and admire veterans who sacrifice their health.

\section{Ethical Statement}

In this study, an informed consent form was obtained from all participants to participate in the study. Also, patient information was not used for any purpose other than conducting the study, and patient information remained confidential.

\section{References}

1. Ebrahimzadeh $\mathrm{MH}$, Soltani-Moghaddas $\mathrm{SH}$, Birjandinejad A, Omidi-Kashani F, Bozorgnia S. Quality of life among veterans with chronic spinal cord injury and related variables. Arch Trauma Res. 2014;3(2):e17917. doi: 10.5812/atr.17917.

2. Javadi M, Hafezi-Nejad N, Vaccaro AR, Rahimi-Movaghar V. Medical complications and patient outcomes in Iranian veterans with spinal cord injury. Adv Clin Exp Med. 2014;23(2):269-75. doi: 10.17219/acem/37075.

3. Azimi G, Divanbeigi A, Doroudi T, Emami A, Yarandi A. Health status of veterans with spinal cord injury during screening program in Tehran 2013: investigating the pulmonary function - a preliminary report. PeerJ Preprints; 2014. doi: 10.7287/ peerj.preprints.766v1.

4. Javadi Parvaneh M, Sahaf R, Delbari A, Kamrani AA, Fadaye Vatan R. Health status of elder spinal cord veterans. Iran J War Public Health. 2017;9(2):97-103. doi: 10.18869/acadpub. ijwph.9.2.97.

5. Magro L, Moretti U, Leone R. Epidemiology and characteristics of adverse drug reactions caused by drug-drug interactions. Expert Opin Drug Saf. 2012;11(1):83-94. doi: 10.1517/14740338.2012.631910.

6. Palleria C, Di Paolo A, Giofrè C, Caglioti C, Leuzzi G, Siniscalchi A, et al. Pharmacokinetic drug-drug interaction and their implication in clinical management. J Res Med Sci. 2013;18(7):601-10.

7. Karimian Z, Kheirandish M, Javidnikou N, Asghari G, Ahmadizar F, Dinarvand R. Medication errors associated with adverse drug reactions in Iran (2015-2017): A P-method approach. Int J Health Policy Manag. 2018;7(12):1090-6. doi: 10.15171/ijhpm.2018.91.

8. Wittich CM, Burkle CM, Lanier WL. Medication errors: an overview for clinicians. Mayo Clin Proc. 2014;89(8):1116-25. doi: 10.1016/j.mayocp.2014.05.007.

9. Boyd CM, Darer J, Boult C, Fried LP, Boult L, Wu AW. Clinical practice guidelines and quality of care for older patients with multiple comorbid diseases: implications for pay for performance. JAMA. 2005;294(6):716-24. doi: 10.1001/ jama.294.6.716.

10. Maher RL, Hanlon J, Hajjar ER. Clinical consequences of polypharmacy in elderly. Expert Opin Drug Saf. 2014;13(1):5765. doi: 10.1517/14740338.2013.827660.
11. Dumbreck S, Flynn A, Nairn M, Wilson M, Treweek S, Mercer SW, et al. Drug-disease and drug-drug interactions: systematic examination of recommendations in 12 UK national clinical guidelines. BMJ. 2015;350:h949. doi: 10.1136/bmj.h949.

12. 12 Edersheim JG, Stern TA. Liability associated with prescribing medications. Prim Care Companion J Clin Psychiatry. 2009;11(3):115-9. doi: 10.4088/pcc.08r00717.

13. Harpaz R, Haerian K, Chase HS, Friedman C. Statistical mining of potential drug interaction adverse effects in FDA's spontaneous reporting system. AMIA Annu Symp Proc. 2010;2010:281-5.

14. Saadat S, Javadi M, Sabet Divshali B, Tavakoli AH, Ghodsi SM, Montazeri A, et al. Health-related quality of life among individuals with long-standing spinal cord injury: a comparative study of veterans and non-veterans. BMC Public Health. 2010;10:6. doi: 10.1186/1471-2458-10-6.

15. Salamati P, Rostami R, Saadat S, Taheri T, Tajabadi M, Ranjbari $\mathrm{G}$, et al. Comparison of health related quality of life between two groups of veteran and non-veteran spinal cord injured patients. Med J Islam Repub Iran. 2015;29:198.

16. Gharakhani M, Razeghi Jahromi S, Sadeghian H, Faghihzadeh $\mathrm{S}$, Kazemi H, Arabkheradmand J, et al. Multiple drug interactions in war-injured veterans. Iran J War Public Health. 2010;2(4):23-8.

17. Bjerrum L, Andersen M, Petersen G, Kragstrup J. Exposure to potential drug interactions in primary health care. Scand J Prim Health Care. 2003;21(3):153-8. doi: 10.1080/02813430310001806.

18. Cruciol-Souza JM, Thomson JC. Prevalence of potential drugdrug interactions and its associated factors in a Brazilian teaching hospital. J Pharm Pharm Sci. 2006;9(3):427-33.

19. Hines LE, MurphyJE. Potentially harmful drug-drug interactions in the elderly: a review. Am J Geriatr Pharmacother. 2011;9(6):364-77. doi: 10.1016/j.amjopharm.2011.10.004.

20. Bethi Y, Shewade DG, Dutta TK, Gitanjali B. Prevalence and predictors of potential drug-drug interactions in patients of internal medicine wards of a tertiary care hospital in India. Eur J Hosp Pharm. 2018;25(6):317-21. doi: 10.1136/ ejhpharm-2017-001272.

21. Mousavi S, Ghanbari G. Potential drug-drug interactions among hospitalized patients in a developing country. Caspian J Intern Med. 2017;8(4):282-8. doi: 10.22088/cjim.8.4.282.

22. Sánchez-Fidalgo $\mathrm{S}$, Guzmán-Ramos MI, Galván-Banqueri M, Bernabeu-Wittel M, Santos-Ramos B. Prevalence of drug interactions in elderly patients with multimorbidity in primary care. Int J Clin Pharm. 2017;39(2):343-53. doi: 10.1007/ s11096-017-0439-1.

23. Schneider KL, Kastenmüller K, Weckbecker K, Bleckwenn M, Böhme M, Stingl JC. Potential drug-drug interactions in a cohort of elderly, polymedicated primary care patients on antithrombotic treatment. Drugs Aging. 2018;35(6):559-68. doi: 10.1007/s40266-018-0550-6.

24. Coelho PV, Brum Cde A. Interactions between antidepressants and antihypertensive and glucose lowering drugs among patients in the HIPERDIA program, Coronel Fabriciano, Minas Gerais State, Brazil. Cad Saude Publica. 2009;25(10):222936. doi: 10.1590/s0102-311x2009001000013.

25. Preskorn SH, Silkey B, Shah R, Neff M, Jones TL, Choi J, et al. Complexity of medication use in the Veterans Affairs healthcare system: Part I: Outpatient use in relation to age and number of prescribers. J Psychiatr Pract. 2005;11(1):5-15. doi: 10.1097/00131746-200501000-00002. 
26. Puetz TW, Youngstedt SD, Herring MP. Effects of pharmacotherapy on combat-related PTSD, anxiety, and depression: a systematic review and meta-regression analysis. PLoS One. 2015;10(5):e0126529. doi: 10.1371/journal. pone.0126529.

27. Stella F, Loureiro JC, Pais MV, Canineu PR, Forlenza OV. Safety limits of antidepressant use plus combinations: focus on cardiovascular function. Curr Drug Metab. 2018;19(8):64152. doi: 10.2174/1389200219666171227203225.
28. Roughead EE, McDermott B, Gilbert AL. Antidepressants: prevalence of duplicate therapy and avoidable drug interactions in Australian veterans. Aust N Z J Psychiatry. 2007;41(4):366-70. doi: 10.1080/00048670701213294.

29. Sciarra T, Ciccotti M, Aiello P, Minosi P, Munzi D, Buccolieri C, et al. Polypharmacy and Nutraceuticals in veterans: pros and cons. Front Pharmacol. 2019;10:994. doi: 10.3389/ fphar.2019.00994. 